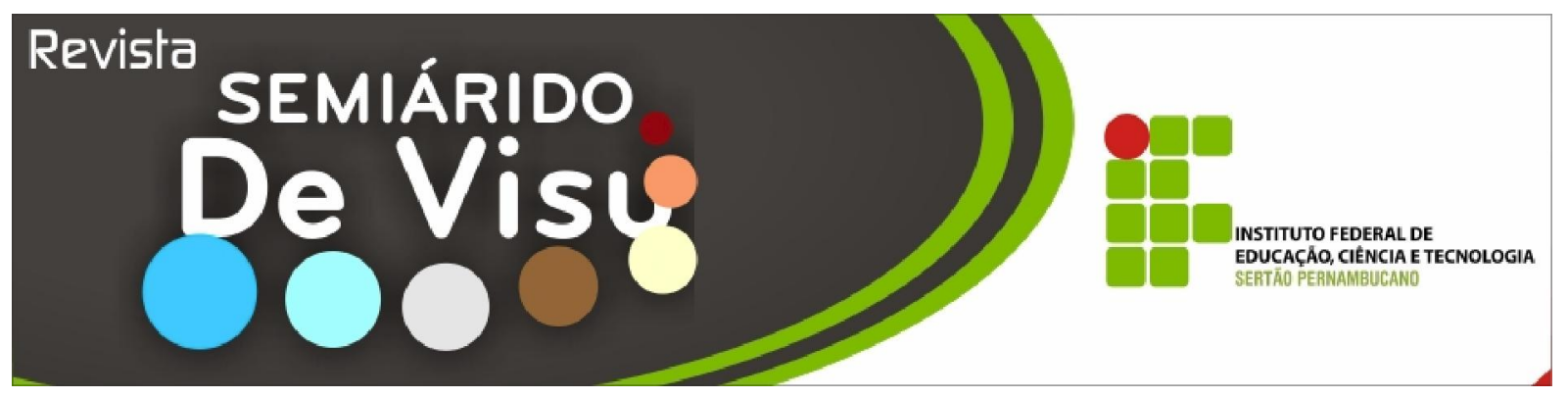

\title{
Elaboração de licores de umbu com diferentes álcoois
}

\author{
Marcelo Iran de Souza Coelho ${ }^{1}$, Luiza Karla Silva Albuquerque ${ }^{2}$, Robson Jesus Mascarenhas ${ }^{1}$, \\ Maria Cláudia Soares Cruz Coelho ${ }^{1}$, Ícaro Cazé Nunes ${ }^{3}$
}

${ }^{1}$ Professores IF SERTÃO-PE, ${ }^{2}$ Tecnóloga em Alimentos IF SERTÃO-PE, ${ }^{3}$ Graduando em Engenharia Química UFCG

RESUMO: O estudo foi realizado com umbus adquiridos aleatoriamente em feiras livres de Petrolina - PE, onde foram selecionados e higienizados. Objetivou-se processar licor de umbu por maceração em quatro tipos de álcool: cereal, tubérculo, gramínea e gramínea desodorizado, testando a preferência quanto ao flavor e aroma, avaliando a intenção de compra. Posteriormente, foram cortados e retirados os pedúnculos, sendo imersos nos diferentes álcoois, identificados em licores: 01 (álcool de gramínea), 02 (gramínea desodorizado), 03 (cereal) e 04 (tubérculo), os quais maceraram por 30 dias. Foram purificados por filtragem, decantação, sifonagem e clarificação. Após adição do xarope, iniciou-se o período de maturação por 90 dias. Os licores foram engarrafados e identificados, para realização da análise sensorial por métodos afetivos quantitativos. Nas análises, os quatro tipos de álcoois são propícios para elaboração do licor de umbu, porém o licor elaborado com álcool de gramínea foi o mais preferido pelos provadores em todos os aspectos analisados, favorecendo o pequeno produtor pelo seu baixo custo, enquanto o produzido com álcool de tubérculo teve menor aceitação.

Palavras-chave: análise sensorial, cereal, gramíneas, maceração, tubérculo.

\section{Preparation of umbu liqueur with different alcohols}

ABSTRACT: The objective of this study was to process umbu liqueur by steeping it in four types of alcohols: cereals, tubers, grass and deodorized grass, testing the preference in relation to flavor and aroma, evaluating purchase intention. The umbus used were randomly purchased in free markets in Petrolina-PE. The umbus had their stems removed and were immersed in different alcohols: 01 (grass alcohol), 02 (grass deodorized alcohol), 03 (cereal alcohol) and 04 (tuber alcohol), where they were macerated for 30 days. They were purified by filtering, decanting, siphoning and clarification. After the addition of syrup, the maturation was started through a period of 90 days. The liqueurs were bottled and labeled in order to perform the sensory analysis through quantitative and acceptance methods. In the analysis, the four kinds of alcohols were suitable for the preparation of umbu liqueur, but the liqueur made with grass alcohol was the most preferred by the judges in all aspects analyzed, which is an advantage to the small producer because of its low-cost. The liqueur produced with tuber alcohol was less accepted.

Key words: sensory analysis, grain, grass, steeping, tuber

\section{Introdução}

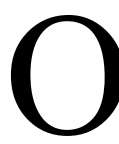

presente trabalho foi realizado no instrumentação laboratório de (cozinha experimental) do IF Sertão-PE, Campus Petrolina, com o objetivo de processar licores de umbu produzidos com diferentes álcoois de vegetais: de gramínea, de gramínea desodorizado, de cereal e de tubérculo, 
Marcelo Iran de Souza Coelho et al.

avaliando o grau de aceitabilidade dos produtos utilizando-se análise sensorial e estatística.

Sabe-se que o umbuzeiro ou imbuzeiro (Spondias tuberosa) é uma árvore de pequeno porte originário dos estados do Piauí, Paraíba, Pernambuco e Bahia. Encontrado em larga escala nestas regiões, o seu fruto, denominado umbu, é explorado comercialmente, para o consumo in natura ou industrial, na elaboração de sucos, polpas congeladas, umbuzadas, sorvetes, licores, xaropes, geléias e/ou doces, demandando, desta forma, pesquisas que ressaltem a adequação de metodologias convencionais e o desenvolvimento de novas tecnologias para o processamento dessa fruta, de forma a promover um aproveitamento mais rentável, mediante a agregação de valor ao produto.

As bebidas alcoólicas sempre ocuparam lugar de destaque nas mais diversas civilizações e são classificadas, segundo a legislação brasileira, em fermentadas (cerveja e vinho), por mistura (licor, amargo e aperitivo, aguardente composta e bebidas mistas), destiladas (cachaça, rum, aguardente, uísque e conhaque) e destilo-retificadas (vodca e gim) (AQUARONE et al., 1993).

Licores são bebidas alcoólicas contendo de 18 a $54^{\circ} \mathrm{GL}$ adocicadas, que se caracterizam pela elevada proporção de açúcar misturada com álcool e aromatizados por substâncias de origem vegetal ou animal, os princípios ativos destes produtos são extraídos usando-se a maceração ou infusão (BRASIL, 1997). Têm propriedades digestivas, estimulantes e reconstituintes, são também usados como aperitivos. Constituem uma alternativa para o aproveitamento de produtos regionais, agregando valores e possibilitando a geração de renda para a família rural.

De acordo com Penha et al. (2003) as fontes de açúcar podem ser o açúcar branco comercial ou o xarope, obtido pela simples fervura do açúcar com água até completa dissolução, procedimento que facilitará a posterior homogeneização com a solução hidroalcoólica.

O licor pode ser denominado de seco, fino ou doce, creme, escarchado ou cristalino, sendo que o licor seco é a bebida contendo mais de trinta e, no máximo, cem gramas de açúcares por litro (BARROS et al., 2008).

Com relação à aceitabilidade de licor de banana, Teixeira et al. (2007), observaram que o licor de menor teor alcoólico e menor teor de açúcar foi o que obteve melhor aceitação.

Enquanto Barros et al. (2008) a elaboração de licor de leite a partir de conhaque de gengibre, cachaça e álcool de cereais resultou em produtos com características físicoquímicas e sensoriais semelhantes.

Penha et al. (2003) verificaram que considerando o teor de álcool, houve diferença para maciez, aroma e sabor frutal, gostos doce e ácido e pungência. Quanto ao teor de açúcar, não houve diferença para nenhum atributo, também não houve evidência de diferenças de médias para aroma e sabor alcoólico de acordo com o teor de álcool.

Segundo Teixeira et al. (2005) a produção artesanal de licores constitui alternativa interessante para proporcionar aumento da renda familiar, pois seu processamento exige tecnologia simples. $\mathrm{O}$ produto final é comercializado em temperatura ambiente e apresenta extensa vida-deprateleira.

\section{Material e Métodos}

O estudo foi realizado com umbus adquiridos aleatoriamente em feiras livres, no município de Petrolina - PE e transportados para o laboratório de instrumentação (cozinha experimental) do IF Sertão-PE, Campus Petrolina, onde foram selecionados, lavados numa pia, com o auxílio de uma vasilha plástica, contendo água clorada $(10 \mathrm{ppm}$ de cloro livre), renovada seguidamente até a limpeza total dos frutos.

Posteriormente, foram retirados os pedúnculos e realizados cortes dos frutos, a fim de facilitar o contato com o álcool e passar as substâncias aromáticas para a solução durante a maceração, sendo imersos em recipientes de vidros previamente esterilizados nos diferentes álcoois, com teor alcoólico variando de $45^{\circ} \mathrm{GL}$ 
Marcelo Iran de Souza Coelho et al.

a $50^{\circ} \mathrm{GL}$, foram identificados em licor 01, preparado com álcool de gramínea (cana-deaçúcar); licor 02, preparado com álcool de gramínea (cana-de-açúcar) desodorizado; licor 03, preparado com álcool de cereal (arroz) e licor 04, preparado com álcool de tubérculo (batata), os quais maceraram por 30 dias.

Após a maceração, foram realizadas a purificação do líquido macerado, por filtragem, decantação, sifonagem e clarificação. Separadamente, preparou-se o xarope com açúcar por dissolução a quente a $65^{\circ}$ Brix. Após o resfriamento completo, adicionou-se o xarope ao líquido macerado. Misturou-se e iniciou-se o período de maturação ou envelhecimento do licor por 90 dias no mínimo. Em seguida, fizeram-se as filtrações necessárias até resultar no licor (no licor límpido) propriamente dito.

Os licores foram engarrafados em recipientes de vidro transparente contendo $250 \mathrm{~mL}$, previamente lavados, esterilizados e tampados com tampas metálicas, por meio engarrafadora manual e rotulados para realização da análise sensorial, pelo teste de categorias qualitativas (Peralta et al., 1999). A aceitabilidade dos licores foi determinada com a participação de consumidores potenciais do produto, utilizando-se uma Escala Hedônica Estruturada de cinco pontos $(1=$ desgostei muito; 3 = não gostei nem desgostei; $5=$ gostei muito), conforme citado em Silva (2004), para os atributos flavor, aroma e intenção de compra.

As avaliações sensoriais foram realizadas de acordo com o método citado em Moraes (1985), em cabines individuais, longe de ruídos e odores, em horários previamente estabelecidos, excluindo uma hora antes e duas horas após o almoço.

A composição do painel de provadores constituiu-se de 53 pessoas escolhidas aleatoriamente, de ambos os sexos, de diferentes faixas etárias e não treinadas, entre eles professores, funcionários e estudantes do curso de Tecnologia de Alimentos de Origem Vegetal do IF Sertão-PE.

As amostras foram servidas em copos descartáveis de $50 \mathrm{~mL}$, codificadas com números. Servidas acompanhadas de biscoito água e sal e água mineral à temperatura ambiente, para remoção do sabor residual entre as amostras e foram apresentadas simultaneamente aos provadores, com a orientação de provarem um por vez, da esquerda para a direita, juntamente com o questionário. Os dados gerados foram analisados estatisticamente pelo software estatístico SPSS 11.0.

\section{Resultados e Discussão}

Os produtos foram analisados sensorialmente quanto ao flavor, ao aroma e a intenção de compra. A partir das tabulações executou-se um tratamento estatístico e realizada uma Análise de Componentes Principais (ACP). De acordo com Faria e Yotsuyanagi (2002), entre as médias das notas dos provadores por atributo sensorial para os licores de umbu com diferentes tipos de álcoois, em que se observou a variabilidade nas respostas dos degustadores (figura 1). 
Marcelo Iran de Souza Coelho et al.

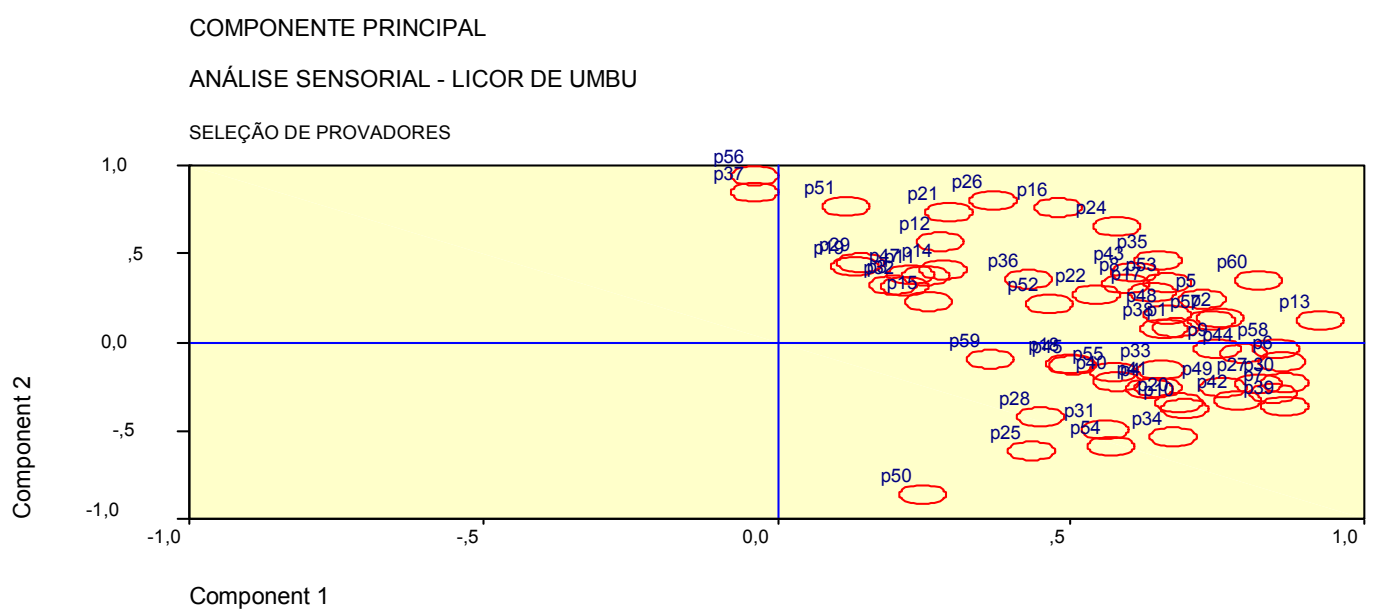

FIGURA 1 - Análise de Componentes Principais (ACP) entre médias de notas dos provadores por atributo sensorial para licores de umbu com diferentes tipos de álcoois.

De acordo com Muñoz et al., (1992), todos os atributos gerados para as amostras de em uma figura que represente a ACP, vetores com medidas mais distantes de zero, correspondem às variações com maior influência sobre o valor do Componente Principal, enquanto, vetores mais próximos de zero indicam que correspondem a uma variável com pequena influência sobre o Componente Principal. Portanto, é possível verificar que licores de umbu correspondem a variações com grande influência.

Com relação à intensidade do flavor, não houve diferença significativa entre os quatro licores (Figura 2), entretanto, o licor 01 destacou-se, obtendo a maior pontuação.

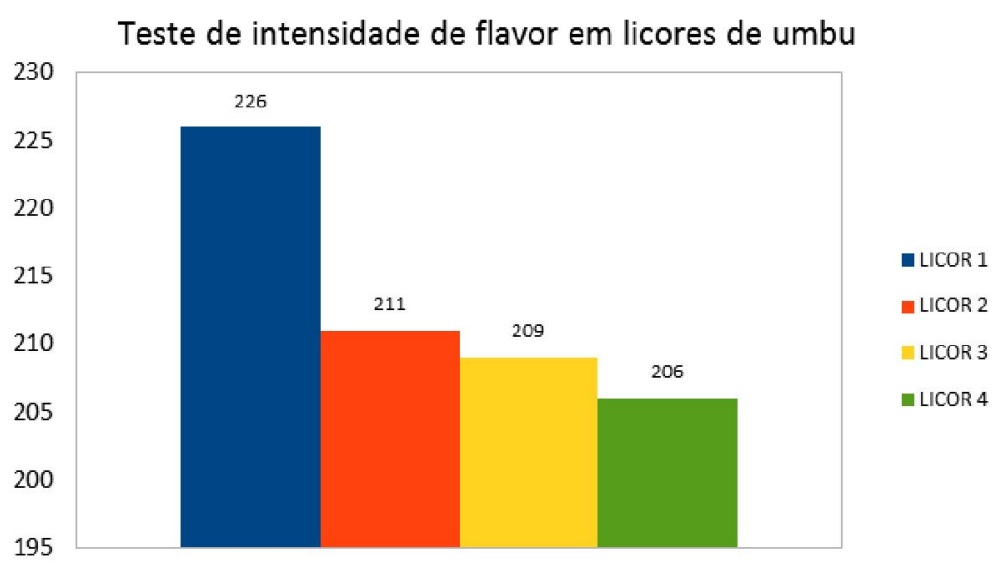

FIGURA 2 - Somatório de notas obtidas no teste de intensidade de flavor.

Comparando os quatro licores quanto à intensidade do aroma, percebeu-se que houve uma diferença significativa entre o licor 01 e o licor 04, como podemos observar na Figura 3, enquanto os licores 02 e 03 não indicaram diferença estatisticamente entre eles. 
Marcelo Iran de Souza Coelho et al.

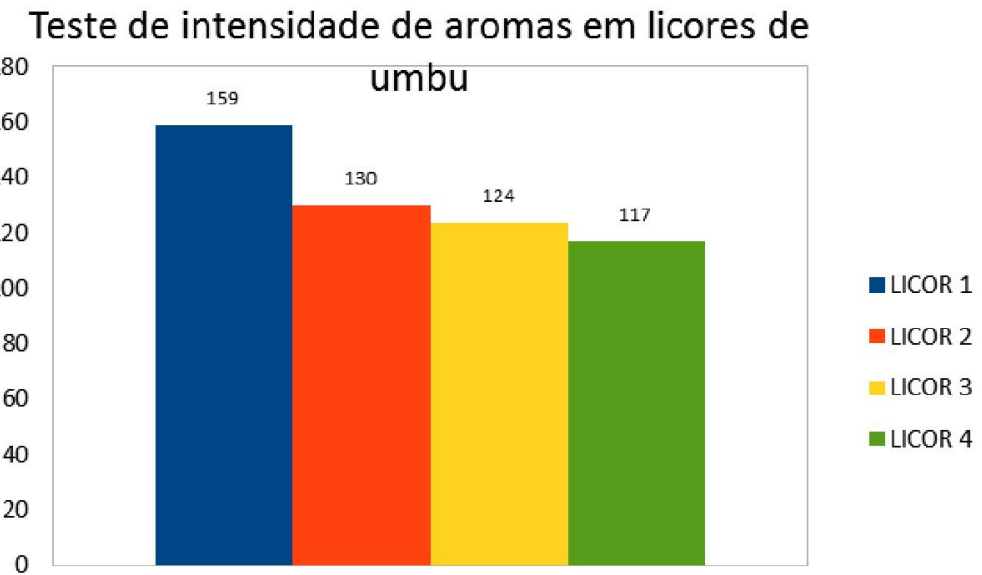

FIGURA 3 - Somatório de notas obtidas no teste de intensidade de aroma.

Penha et al. (2003) analisando o efeito dos teores de álcool e açúcar no perfil sensorial de licor de acerola, observaram diferenças marcantes nas médias de atributos como maciez, sabor frutal e pungência, segundo os teores de álcool e, ressaltaram ainda que o comportamento díspar do aroma e sabor alcoólicos encontrados se referem à grande dificuldade de percepção da variação e intensidade destes atributos.

Cipriano et al. (2002), com relação ao teor de açúcar, observaram que para o mesmo percentual de álcool de cereais e aguardente na infusão o produto final possui graus Brix diferenciados, levando a crer que a extração é mais eficiente com álcool de cereais do que com aguardente.

Os resultados de Barros et al. (2008) demonstraram que o uso de conhaque de gengibre, cachaça e álcool de cereais resultou em produtos com características sensoriais semelhantes. Esse fato pode ser atribuído à adição dos compostos aromáticos que mascaram o flavor característico das fontes alcoólicas.

Com relação à intenção de compra, observou-se que houve uma diferença significativa entre o licor 01 e o licor 04 , pois os degustadores certamente comprariam o licor 1 quando comparado ao licor 4. Percebeu-se ainda que com relação aos licores 02 e 03 não foi demonstrado nenhuma diferença.

\section{Conclusão}

Os quatro tipos de álcoois estão propícios para o processamento de licor de umbu, favorecendo o pequeno produtor que pode optar pelo álcool com baixo custo, utilizando a produção de licor como fonte de renda complementar.

\section{Referências}

AQUARONE, E.; LIMA, U.A.; BORZANI, W. Alimentos e bebidas produzidas por fermentação. São Paulo: Edard Blucher, 1993, v. 5,227 p.

BARROS, J. C.; SANTOS, P. A. dos; ISEPON, J. S.; SILVA, J. W. da; SILVA, M. A. P. da. Obtenção e avaliação de licor de leite a partir de diferentes fontes alcoólicas.Revista Global Science and Technology. v. 1, n. 4, p. 27-33, 2008.

BRASIL. Decreto n. 2.314, de 4 de setembro de 1997. Regulamenta a lei $n^{\circ} 8.918$ de 14 de julho de 1994, que dispõe sobre a padronização, a classificação, o registro, a inspeção, a produção e a fiscalização de bebidas. Diário Oficial da República Federativa do Brasil, 
Marcelo Iran de Souza Coelho et al.

Brasília, 5 set. 1997. Seção 1. p.19549 -19555.

CIPRIANO, L. W.; SANTOS, M. N. G.; PAIXÃO, A. E. A.. Processamento de licor a partir de frutas regionais. In: CONGRESSO BRASILEIRO DE FRUTICULTURA, 17, Belém, 2002. Anais. Belém, Sociedade Brasileira de fruticultura, 2002. CD ROM.

FARIA, E. V. de YOTSUYANAGI, K. Técnicas de análise sensorial. Campinas, SP: LAFISE/ITAL, 2002. 116 p.

MORAES, M. A. C. Métodos de avaliação sensorial dos alimentos. Campinas: Unicamp/FEA, 1985, 85p.

MUÑOZ, A.M., CIVILlE,G.V., CARR,B.T. Sensory evaluation in quality control. New York: Van Nostrand Reinhold, 1992. 240 p.

PENHA, E. M.; DELLA MODESTA, R. C.; GONÇALVES, E. B.; SILVA, A. L. S.; MORETTI, R. H. Efeito dos Teores de Álcool e Açúcar no Perfil Sensorial de Licor de Acerola.
Brazilian Journal Food Technology. v.6, n.1, p.33-42, 2003.

PERALTA, M. O. U.; HUAPAYA, M. D. A.; MOLINA, O. G. Evaluación sensorial de los alimentos. Lima: Editorial Agraria, 1 ed., 1999, $197 \mathrm{p}$.

SILVA, M. A. A. P. Métodos de Avaliação Sensorial dos Alimentos, FEA/UNICAMP, 2004.

TEIXEIRA, L. J. Q.; RAMOS, A. M.; CHAVES, J. B. P.; SILVA, P. H. A. da; STRINGHETA, P. C. Avaliação tecnológica da extração alcoólica no processamento de licor de banana. Boletim do Centro de Pesquisa e Processamento de Alimentos. v. 23, n. 2, p. 329-346, 2005.

TEIXEIRA, L. J. Q.; RAMOS, A. M.; CHAVES, J. B. P.; STRINGHETA, P. C. Testes de aceitabilidade de licores de banana. Revista Brasileira de Agrociência. v. 13, n. 2, p. 205 209, 2007. 